\title{
VEHICLE BREAKDOWN ASSISTANCE
}

\author{
NivethaM $^{1}$ and SujthaS ${ }^{2}$ Abinaya $^{3}$ \\ ${ }^{1}$ Department of Computer Application, Francis Xavier Engineering College \\ ${ }^{2}$ Department of Computer Application, Francis Xavier Engineering College \\ ${ }^{3}$ Department of Computer Application, Francis Xavier Engineering College
}

\begin{abstract}
This application is used to find nearby area mechanics while we suddenly stranded on the remote locations with mechanical issues of our vehicle. It is a good solution for the people who seek help in the remote locations. In this, the approved mechanics are enlisted in this application. Also they are under monitored by this system for not charging any extra service fee from the users. This can be monitored by the admin through the user feedback based on their service. The registered users can access this application. This application will help to reduce wasting user time to found a proper mechanic. This application will allow user to make payment for a vehicle repair in a reasonable price.
\end{abstract}

\section{KEYWORDS}

Vehicle, Assistance, Travel, Spare-parts, Mechanic shop, Power, Service

\section{INTRODUCTION}

Today most of people use their own vehicle for travel. While travelling most of us are troubling with breakdown of our vehicle on the road. This is a worst experience that they have to face. When our vehicle suddenly breakdown on the road, the user have to search for mechanic and have to see a spare-part shops near to their location. At that time we can't able to search for a good mechanic and we have to arrange some other transportation. By using this application the user can find suitable mechanic. The most advantage is the user can find a mechanic based on their user location and make payment. Varun Kapadi, SaigitaGuruju, Bhupesh Bojja, Prof. NilimaNikam had discussed about the application which directly connect with google GPS system and it shows the users current location.This project will show the name and address or location of all hospital those are in the range and the user can able to select any one hospital. VibhaviArtigala, H.DhanukaNadeeshani have discussed about the application Helpme. This will show the user location and direct the nearest service provider to user and the chat platform where the user can ask some relevant questions to the mechanic. Miss. K. Iswarya Miss. D. Devaki Mr. E. Ranjith have discussed about the application which helps to find nearby service centres as well as the fuel stations in case of any emergency situations like insufficient fuel on vehicles and un-avoided incidents like puncture, break failure, doping etc. Akhila VKhanapuri, AnaghaShastri, Gareth Dsouza, Shannon Dsouza has discussed about the android application is proposed which monitors parameters like Engine RPM, fuel status, throttle position through an On board Diagnostics (OBD-II) being able to help amateur drivers with gear changing and provide assistance in case of vehicle breakdown. Khoo JinSheng, Ahma SuhaimiBahurudin, Kamal Karkonasasi has discussed in this paper that start with the analysis of the car breakdown 
incidents on the road. It expects that through some research, the statistics of car breakdowns can be obtained to see if this project is helpful to those in need.

\section{Problem Statement}

The problem while travel is breakdown of our vehicle. In this situation, the only way is to look for some other transportation at that time of issue and then they need to get a mechanic to the particular location at which they have left their vehicle. In this application, the mobile users can get nearby area mechanics by searching at anytime and anywhere. The admin can access the shop details and check whether the registered shop is licensed or not and provide approval.

\section{Existing System}

- In an existing system there are users who have their own mechanic number and it is also difficult for them to arrive at time.

- And it is also possible to find out the suitable mechanic for the desired service at remote locations.

- The only way is to look for any other transportation at that time of issue and then they need to get a mechanic to the particular location at which they have left their vehicle.

\section{Proposed system}

- The proposed application helps to find the nearby mechanics easily and quickly.

- This application show the user location and direct the nearest service provider to the user.

- It allows us to search the nearby mechanics from different locations and call to the mechanic.

- The user can make payment based on their service through this application.

\section{Architecture Diagram}

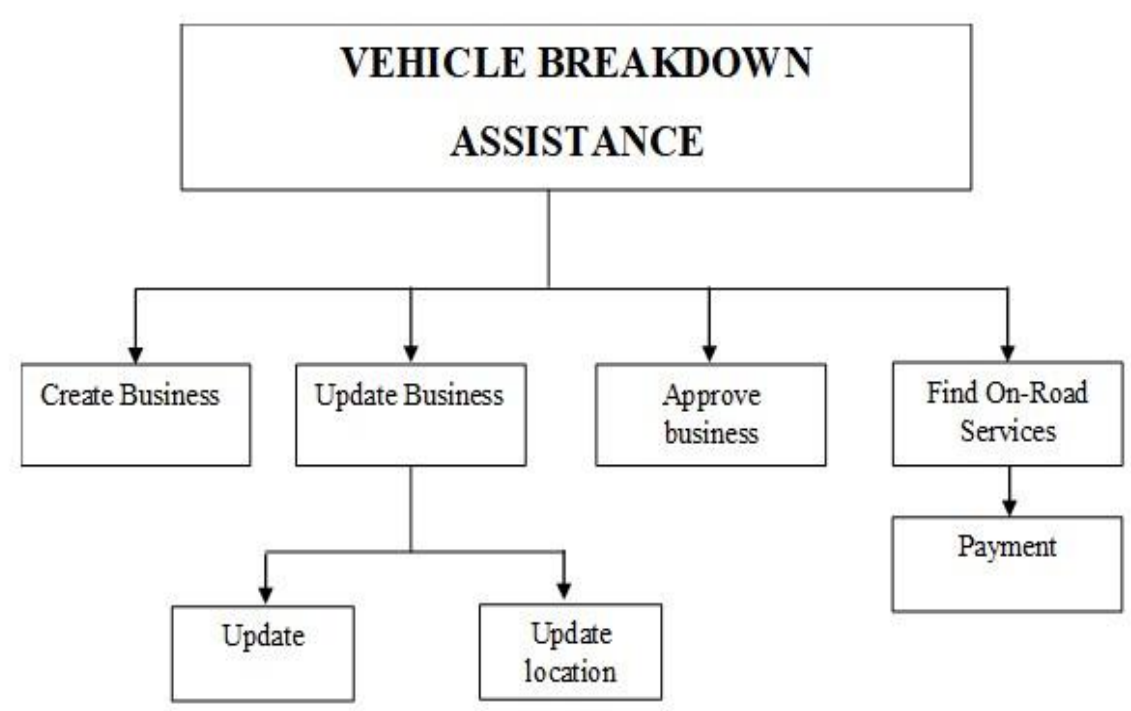

Figure 1: Architecture Diagram 


\section{EXPERIMENT AND RESULTS}

\section{Create Business}

In this module, the business owner can add their business details like Mechanic name, Services, Availability and Address. Once the business is created the admin will provide the approval for the business.

\section{Update Business}

In this module, the business owner can upload the location and can edit and view the details.

\section{Approve Business}

In this module, the admin can provide the approval for the registered business and can view the user details and ratings.

\section{Find on road services}

In this module, the user can search the nearby mechanics according to their location.The user can call or message to the particular mechanics who is nearby to their locations. PAYMENT: In this module, the user make the payment based on the services.

\section{Admin}

The admin will provide approval for the registered business and can view user details.

\section{Database Collection}

The database will maintain all records about the mechanic shop details and user details in this application. So that it is easy to access and retrieve data from the database. The user can search the nearby mechanics shop which is stored in the database.

User details and business owner details are stored in database and it can be viewed by admin. The admin will provide approval for the registered business. The admin will keep on checking the feedback of the user to know the service provided by the mechanic shop. 


\section{Output Screen}

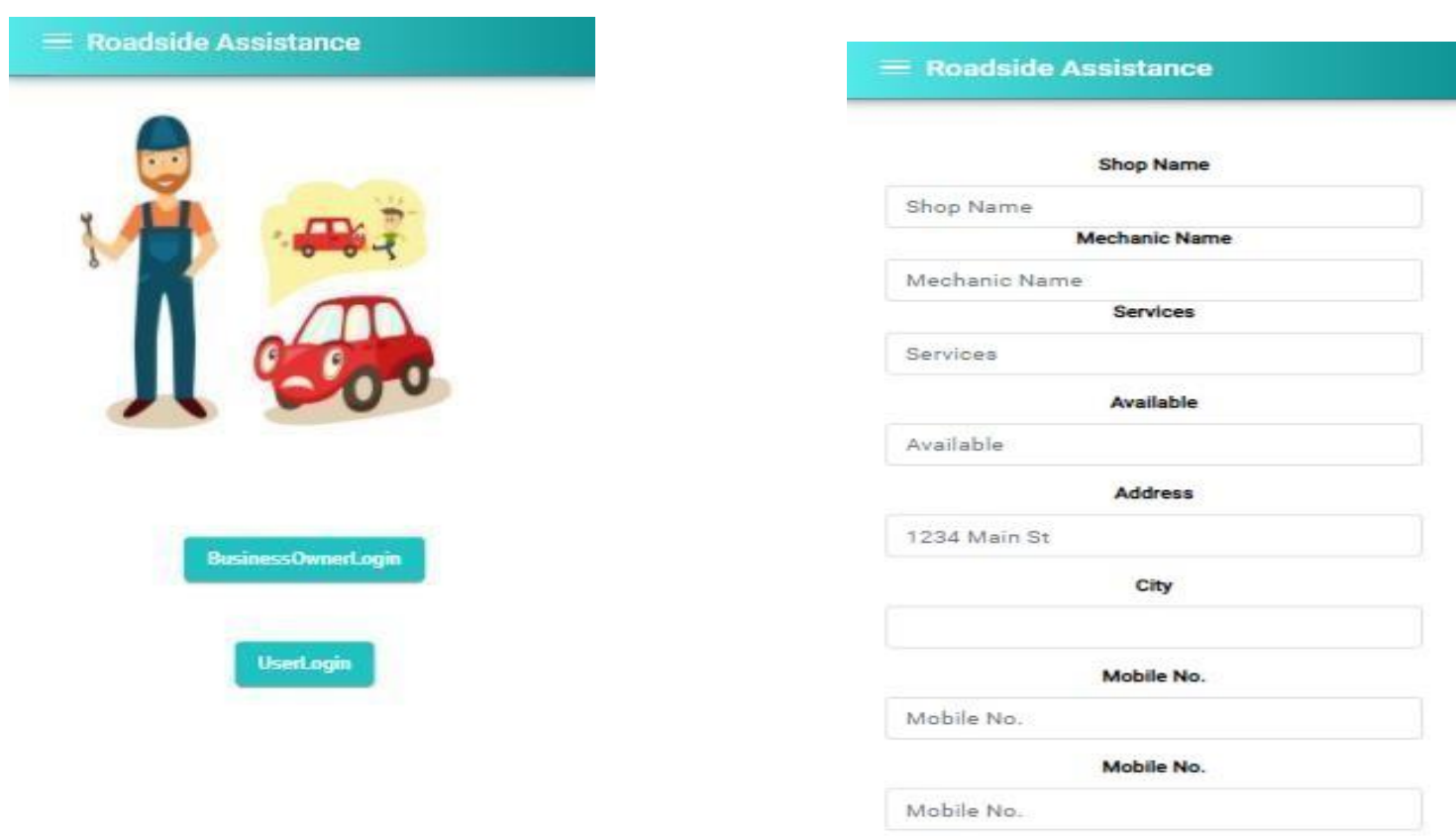

Figure 2:Login page

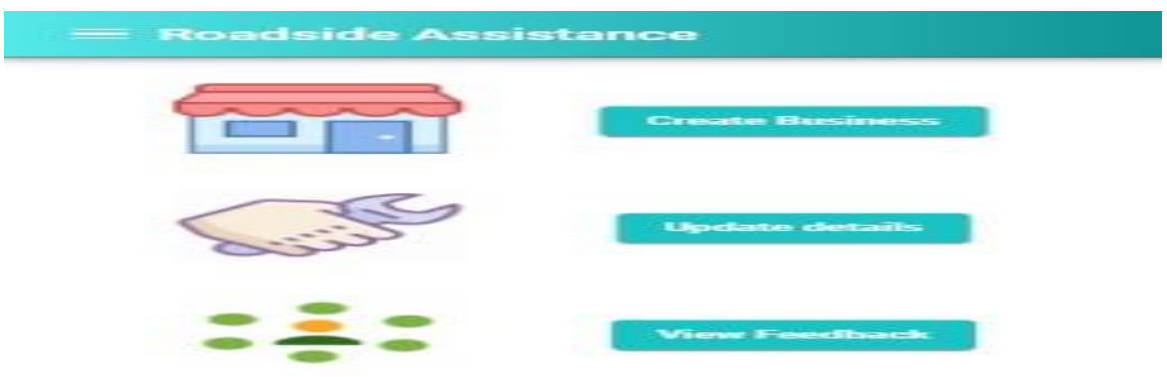

Figure 3 Create Bussiness 


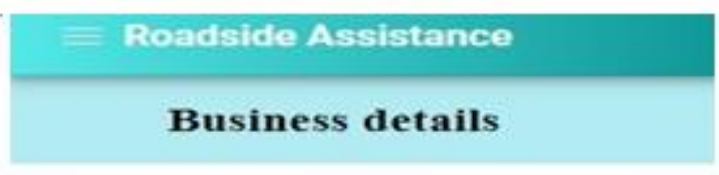

\begin{tabular}{|c|c|}
\hline Id & 1 \\
\hline Shop Name & Best Wheels \\
\hline Mechanic Name & Jai \\
\hline Services & All $2 \& 4$ wheelers \\
\hline Available & Mon-sat \\
\hline Ciry & Tuticorin \\
\hline Latínde & 8.0462348652698 \\
\hline Longitude & 7.4331016540527 \\
\hline Eadit & Updatre tocation \\
\hline
\end{tabular}

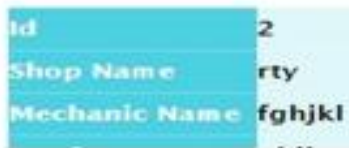

Figure 4:Business Details

\section{E Roadside Assistance}

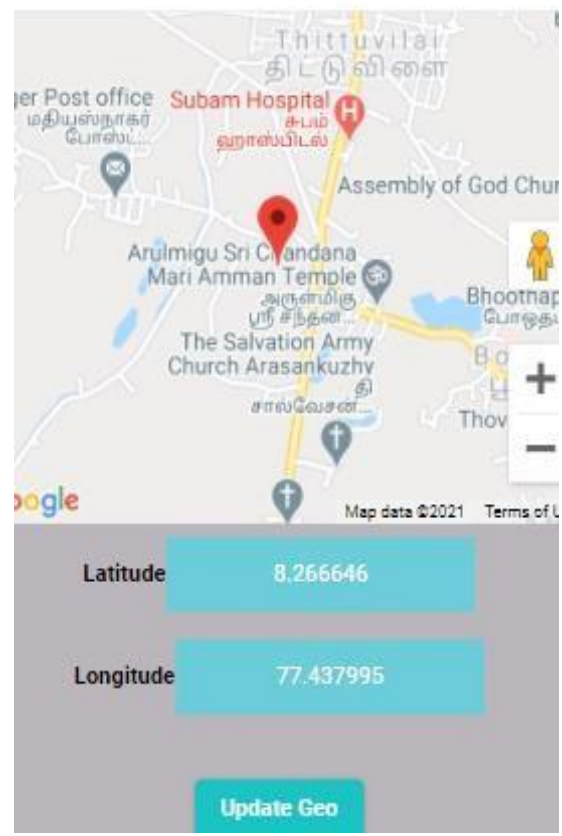

Figure 5:Find 


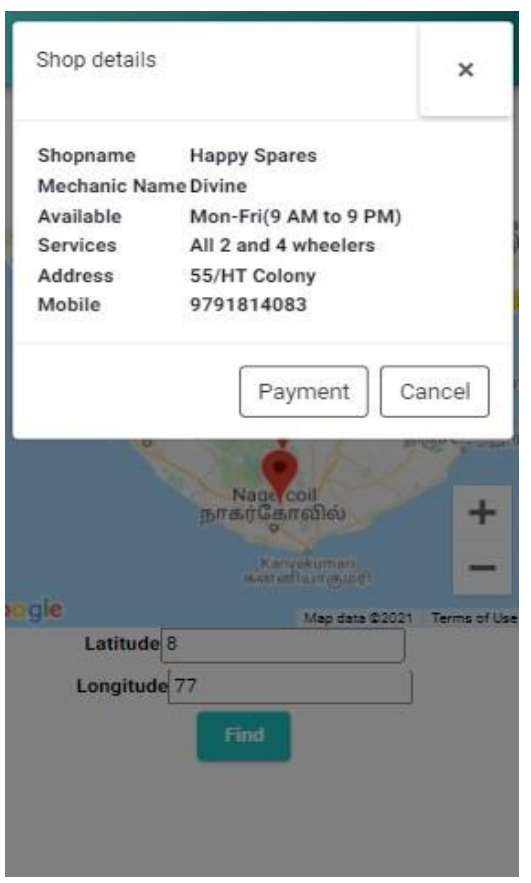

Figure 6:Shop Details

\section{E Roadside Assistance}
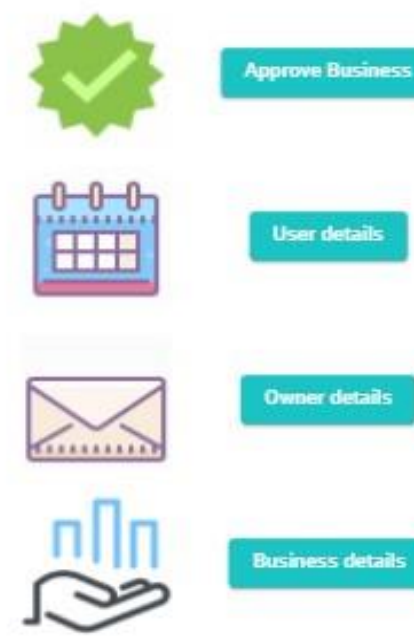

Figure 7:Business Approval 


\section{Roadside Assistance}

Iip

\begin{tabular}{|c|c|c|c|}
\hline $\begin{array}{l}\text { VTY } \\
\text { lony }\end{array}$ & Tuticorin & 9876546795 & Reject \\
\hline injk & ghjk & 9875678483 & Reject \\
\hline $\begin{array}{l}\text { rt } \\
\text { lony }\end{array}$ & Kanniyakumari & 7904804796 & Reject \\
\hline $\begin{array}{l}\text { i KJ } \\
\text { lony }\end{array}$ & Kanniyakumari & 9791814083 & Reject \\
\hline $\begin{array}{l}\text { iH } \\
\text { lony }\end{array}$ & Kanniyakumari & 9789146644 & Reject \\
\hline Inh & Nanamail & QR7K5A222A & \\
\hline
\end{tabular}

Figure 8:Details

\section{= Roadside Assistance}

\section{Business details}

\begin{tabular}{|l|l|}
\hline Name & nive \\
Email & nive113@gmail.com \\
Address & $113 / J K$ colony \\
City & Nagercoil \\
Zip & 629852 \\
\hline
\end{tabular}

\begin{tabular}{l|l}
\hline Name & $\begin{array}{l}\text { indhu } \\
\text { indhu1 13@gmail.com }\end{array}$ \\
Emait & $112 / \mathrm{HL}$ colony \\
Address & Nagercoil \\
City & 629852 \\
Zip & \\
Name aaa
\end{tabular}

Figure 9:Other Business Details 


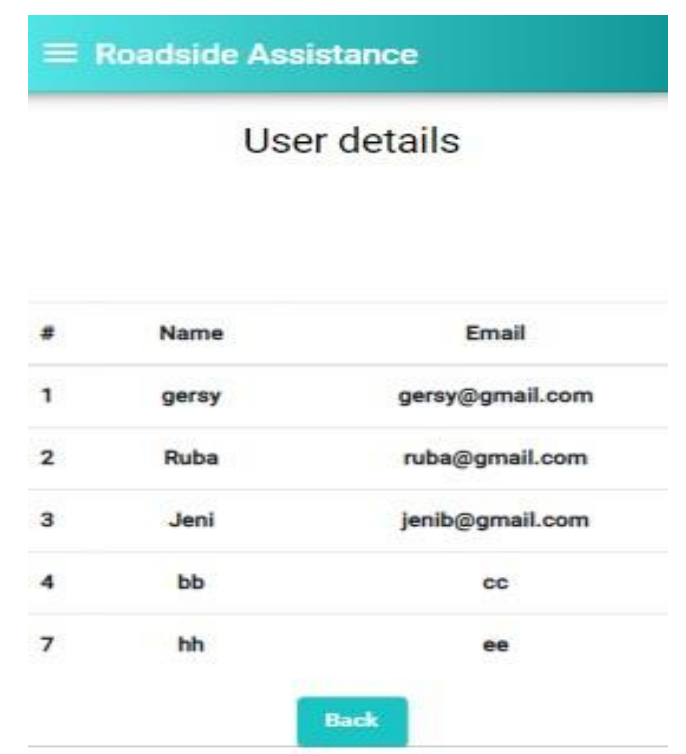

Figure 10: User Details

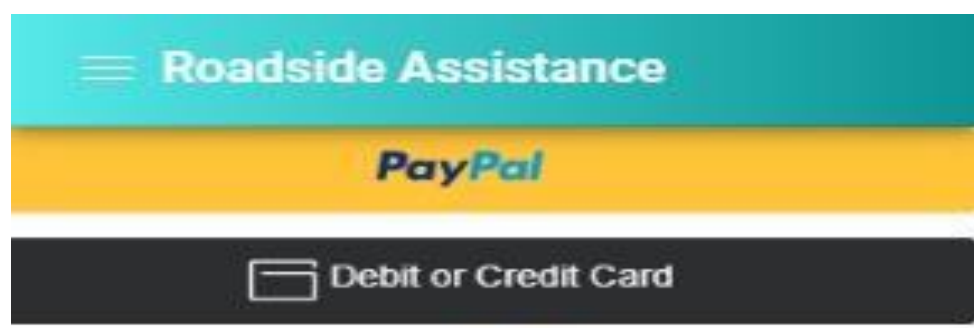

Powerad by Paypal

Figure 11:Paypal

\section{Performance Analysis}

The existing and proposed systems are analysed. The problems can be easily rectified with this concept. Nearly $70 \%$ of the performance has been increased.

\section{CONCLUSION}

When the vehicle breakdown occurs the driver have to see a mechanic or the repair shop. The driver has to ask for help from the people. By using this application, the user can find mechanic based on user location. The user can get the mechanical help directly and easily. This is help to save user's time while the traveling. When the breakdown occur, user can fix their vehicle immediately. That make comfortable the user. They won't make tired their journey.

\section{FUTURE ENHANCEMENT}

In Future, the vehicle and spareparts shop will be categorized according to the vehicle model. That is help to user found their spare-parts according to the type of the vehicle by saving their time. In addition to that the list of hospitals and Fuels stations can be added. 


\section{REFERENCES}

[1] Lee, Shuiping Wei, Bangyan Ye, Zhiguang Fu, "Research on GPS Positioning Information Transfer Based on Wireless Network," 2007, 28(6): 589-592.

[2] Jianxun Zhao, "Mobile Location Services Development and Implementation Based on Android Platform," Modern Business Trade Industry. pp 271-272. October 2010.

[3]. "A public safety application of GPSenabled smartphones and the android operating system"- Systems, Man and Cybernetics, 2009. SMC 2009. IEEE International Conference-Whipple, J.Inf. Syst. Eng. Dept., Southwest Res. Inst., San Antonio, TX, USA Arensman, W. ;Boler, M.S.

[5]. "Developing an Android based learning application for mobile devices", Telematics and Information Systems (EATIS), 2012 6th Euro American Conference, de Clunie, G.T.Fac. de Ing. de Sist., Computacionales, Univ. Tecnol. de Panama, Panama City, Panama Serrao, T. ; Monteiro Braz, J.R.- . Serr o, T. Rangel, N. Castillo, A. G mez, B. Rodrguez, . de Barraza, . Riley, J.

[6]. The Interaction Design Foundation. (2020). Prototyping: Learn Eight Common Methods and (Anon., 2020)Best Practices. [online] Available at: https://www.interactiondesign.org/literature/article/prototyping-learn-eight-common-methods-and-best-practices [Accessed 20 Jan. 2020].

[7] The Interaction Design Foundation. (2020). Prototyping: Learn Eight Common Methods and Best Practices. [online] Available at: https://www.interaction-design.org/literature/article/prototypinglearn-eight-common-methods-and-best-practices [Accessed 20 Jan. 2020.

[8]. Monica, 2018. A Car Breakdown Service Station Locator System. INTERNATIONAL JOURNAL OF ADVANCE SCIENTIFIC RESEARCH, 3(4), pp. 13-16

[9]. Florian, e., 2017. Google Patent. [Online] Available at: https://patents.google.com/patent/US20190171758A1/en [Accessed 17 January 2020].

[10].Reichardt, e., 2002. Car Talk 2000. [Online] Available at: https://ieeexplore.ieee.org/abstract/document/1188007 [Accessed 17 December 2019]. 


\section{AuThORS}

Ms.M.Nivetha doing final year MCA in Francis Xavier Engineering College.

Mrs.S.Sujitha working as Assistant Professor in the department of Master of Computer Applications, Francis Xavier Engineering College. Her area of intrest in Wireless Sensor Networks.

Ms. V.Abinaya doing first year MCA in Francis Xavier Engineering College.

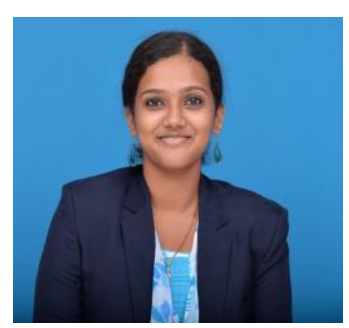

